\title{
Epac1 deficiency inhibits basic fibroblast growth factor-mediated vascular smooth muscle cell migration
}

\author{
Yuko Kato $^{1,2} \cdot$ Utako Yokoyama $^{1}$ (D $\cdot$ Takayuki Fujita $^{1} \cdot$ Masanari Umemura $^{1} \cdot$ Tetsuo Kubota $^{2} \cdot$ Yoshihiro Ishikawa $^{1}$
}

Received: 10 May 2018 / Accepted: 24 July 2018 / Published online: 6 August 2018

(c) The Physiological Society of Japan and Springer Japan KK, part of Springer Nature 2018

\begin{abstract}
Vascular smooth muscle cell (VSMC) migration and the subsequent intimal thickening play roles in vascular restenosis. We previously reported that an exchange protein activated by cAMP 1 (Epac1) promotes platelet-derived growth factor (PDGF)-induced VSMC migration and intimal thickening. Because basic fibroblast growth factor (bFGF) also plays a pivotal role in restenosis, we examined whether Epac1 was involved in bFGF-mediated VSMC migration. bFGF-induced lamellipodia formation and migration were significantly decreased in VSMCs obtained from Epac1 ${ }^{-1-}$ mice compared to those in Epac1 ${ }^{+/+}$-VSMCs. The bFGF-induced phosphorylation of Akt and glycogen synthase kinase $3 \beta$ (GSK3 $\beta$ ), which play a role in bFGF-induced cell migration, was attenuated in Epac1 ${ }^{-1-}$-VSMCs. Intimal thickening induced by the insertion of a large wire was attenuated in Epac1 $1^{-1-}$ mice, and was accompanied by the decreased phosphorylation of GSK3 $\beta$. These data suggest that Epac1 deficiency attenuates bFGF-induced VSMC migration, possibly via Akt/GSK3 $\beta$ pathways.
\end{abstract}

Keywords Exchange protein activated by cAMP $1 \cdot$ Intimal thickening $\cdot$ Basic fibroblast growth factor $\cdot$ Vascular smooth muscle cells $\cdot$ Migration

\section{Introduction}

Intimal thickening that occurs after vascular injury resulting from percutaneous coronary intervention is a major clinical problem [1]. This thickening is the fundamental process of wound healing in which the vascular smooth muscle cells (VSMCs) migrate toward the internal lumen and proliferate within the innermost layer of the arterial wall [2]. Although drug-eluting stents significantly reduce intimal thickening, repeat revascularization remains relatively common [3],

Electronic supplementary material The online version of this article (https://doi.org/10.1007/s12576-018-0631-7) contains supplementary material, which is available to authorized users.

Utako Yokoyama

utako@yokohama-cu.ac.jp

$\triangle$ Yoshihiro Ishikawa

yishikaw@med.yokohama-cu.ac.jp

1 Cardiovascular Research Institute, Yokohama City University, 3-9 Fukuura, Kanazawa-ku, Yokohama, Kanagawa 236-0004, Japan

2 Department of Immunopathology, Tokyo Medical and Dental University, Graduate School of Medical and Dental Sciences, Tokyo, Japan and the risk of definite late stent thrombosis has emerged as a major concern [4]. It is thus important to elucidate the molecular mechanisms involved in the pathological process of intimal thickening.

VSMC migration is a critical event in restenosis [2, 5], and is mediated by the cytokines and growth factors released from the arterial wall $[6,7]$. Basic fibroblast growth factor (bFGF) and platelet-derived growth factor (PDGF)-BB are released by endothelial cells, macrophages, and VSMCs at the vascular injury site [8]. Both bFGF and PDGF-BB contribute significantly to VSMC migration and the subsequent intimal thickening $[6,9]$.

We previously demonstrated that an exchange protein activated by cAMP (Epac) induced the migration of VSMCs and other cell types [10-12]. When Epac1 was silenced, PDGF-BB-induced VSMC migration and mechanical injuryinduced intimal thickening were attenuated [13]. Another line of study reported that genetic knockdown of the Epac1 gene reduced intimal thickening in a mouse carotid artery ligation model [14]. The contribution of Epac1 to bFGFinduced VSMC migration and intimal thickening, however, remains unknown.

bFGF activates the phosphoinositide 3-kinase (PI3 K)/ protein kinase $\mathrm{B}(\mathrm{Akt})$ pathway and promotes cell migration 
[15-18]. PI3 K/Akt signaling was activated after balloon catheter injury of rat carotid arteries [19]. Epac also stimulates PI3 K/Akt signaling pathways in a variety of cell types [20-23]. In Epac1-deficient VSMCs, the protein expression of the PI3 K p110 isoform and the phosphorylation of Akt at $\mathrm{Ser}^{473}$ was significantly decreased [14]. These findings suggest that bFGF and Epac share downstream signaling pathways, namely, PI3 K/Akt. We therefore hypothesized that the downstream signaling of Epac1 is involved in bFGFinduced VSMC migration and neointima formation. Here, we demonstrate the effect of Epac1 deficiency on bFGFinduced migration using a primary culture of VSMCs from Epac1 $^{-/-}\left(\right.$Epac1 $^{-/-}$-VSMCs $)$.

\section{Method}

\section{Reagents}

Anti-FGFR 1 and anti-phosphorylated cofilin antibodies were purchased from Santa Cruz Biotechnology (San Diego, CA, USA). Anti-Forkhead box transcription factor O1 (FOXO1) antibody was purchased from abcam (Cambridge, MA). Anti-glycogen synthase kinase $3 \beta$ (GSK3 $\beta$ ), anti-phosphorylated GSK3 $\beta$ ( $\operatorname{Ser}^{9}$ ), anti-Akt, anti-phosphorylated Akt $\left(\mathrm{Ser}^{473}\right)$, anti-p70 ribosomal protein S6 kinase (S6 K), anti-phosphorylated S6 K ( $\mathrm{Thr}^{389}$ ), and antiphosphorylated FOXO1 $\left(\mathrm{Ser}^{256}\right)$ antibodies were purchased from Cell Signaling (Beverly, MA, USA). Hoechst 33342, rhodamine conjugated anti-F-actin antibody, Alexa Fluor 488 anti-rabbit IgG antibody, and Alexa Fluor 594 anti-rabbit IgG antibody were purchased from Life Technologies (Carlsbad, CA, USA). Recombinant human bFGF protein was purchased from Thermo Fisher Scientific (San Jose, CA, USA). Poly-L-lysine was purchased from Sigma (St. Louis, MO, USA). Elastase type II-A, trypsin inhibitor type I-S, bovine serum albumin V, penicillin-streptomycin solution, and Dulbecco's modified Eagle's medium (DMEM) were purchased from Sigma-Aldrich. Collagenase type II was purchased from Worthington Biochemical (Lakewood, NJ, USA). Collagenase dispase was purchased from Roche Diagnostics (Tokyo, Japan). Fetal bovine serum (FBS) was purchased from Equitech-Bio (Kerrville, TX, USA). TissueTek OCT was purchased from Sakura Finetek (Torrance, CA, USA).

\section{Animals}

All animals were cared for in compliance with the guiding principles of the American Physiological Society. The experiments were approved by the Ethical Committee of Animal Experiments at Yokohama City University (reference number: F-A-14-108). The generation of Epac1-deficient mice was described previously [24]. Epac1 ${ }^{+/+}$and $\mathrm{Epac}^{-/-}$littermate mice (3-8 months old) were obtained from heterozygote crosses.

\section{Isolation and culture of mouse VSMCs}

VSMCs were isolated from the thoracic aorta of mice using an explant method as previously described [13]. Briefly, after mice were euthanized with $100 \mathrm{mg} / \mathrm{kg}$ of pentobarbital (Kyoritsu Seiyaku, Tokyo, Japan), the aortae were isolated. The aortae were incubated with a collagenase enzyme mixture that included elastase type II-A, trypsin inhibitor type I-S, bovine serum albumin V, collagenase type II, and collagenase dispase, and the tunica media was separated from the adventitia. The tunica media was then cut into small pieces and plated on a poly-L-lysine-coated culture dish. VSMCs were grown in DMEM supplemented with 20\% FBS and $1 \%$ penicillin-streptomycin and in air supplemented with $5 \% \mathrm{CO}_{2}$ at $37^{\circ} \mathrm{C}$. Cells within 10 passages were used in the experiments.

\section{Cell migration assay}

Cell migration was assessed by tracking the path length as previously described [13]. After VSMCs were serum starved for $48 \mathrm{~h}$, cells were treated with or without $10 \mathrm{ng} / \mathrm{ml}$ of bFGF for $8 \mathrm{~h}$. Path lengths of VSMCs were measured using timelapse microscopy (TE2000 Eclipse, Nikon, Tokyo, Japan). Images were recorded at 20-min intervals during the tracking, and the nucleus of each cell was manually traced for each frame. We performed three independent experiments and found statistically similar results.

\section{Immunoblotting}

VSMCs were lysed and sonicated in a lysis buffer containing $150 \mathrm{mmol} / \mathrm{Na}_{2} \mathrm{CO}_{3}$ [pH 11.0] and $1 \mathrm{mmol} / \mathrm{l}$ EDTA. Protein expression in whole cell lysates was analyzed by immunoblotting as described previously [13].

\section{Immunocytochemistry}

Immunocytochemistry was performed as previously described [13]. Briefly, VSMCs cultured on 12-mm glass coverslips were serum starved for $48 \mathrm{~h}$ and then stimulated for 30 min with DMEM alone (control) or bFGF (10 ng/ $\mathrm{ml})$. Fixed cells were incubated with primary antibodies overnight at $4{ }^{\circ} \mathrm{C}$. DNA was stained with Hoechst solution. Morphometric analysis was performed using Nikon TE2000E (Tokyo, Japan). 


\section{Femoral artery injury model}

Transluminal mechanical injury of the femoral artery was induced by the insertion of a large wire $(0.38 \mathrm{~mm}$ in diameter, C-SF-15-15, Cook, Bloomington, IN, USA) as previously described [13]. The arteries were harvested 2 weeks after injury and were embedded in OCT compound and snap-frozen in liquid nitrogen. Frozen sections were stored at $-80{ }^{\circ} \mathrm{C}$ until use.

\section{Immunohistochemistry}

Immunohistochemistry was performed as previously described [13]. Frozen tissue sections were incubated with a primary antibody overnight at $4{ }^{\circ} \mathrm{C}$. The slides were washed 3 times with Tween 20/PBS for 5 min and then incubated with a secondary antibody for $1 \mathrm{~h}$. After six washes with Tween 20/PBS, the DNA was stained with Hoechst solution.

\section{Statistical analysis}

Data are expressed as mean \pm standard error of the mean (SEM). Statistical analysis was performed using unpaired Student's $t$-test in Fig. 1c. A two-way analysis of variance (ANOVA) followed by Bonferroni's multiple comparison test was used for Figs. 1b, 2b, 3b, d, 4b, d. A value of $p<0.05$ was considered significant.
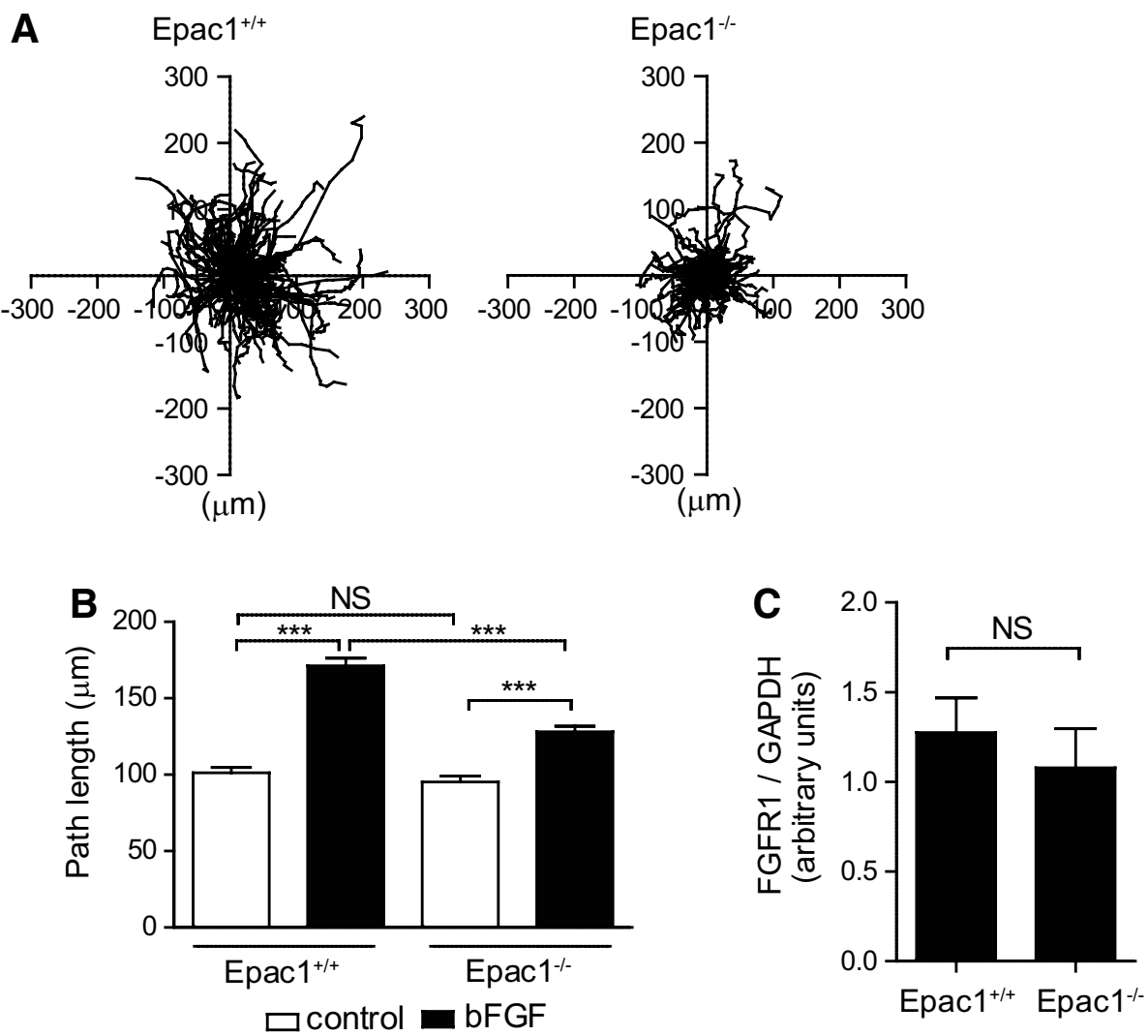

Fig. 1 The effect of Epac1 deficiency on bFGF-induced VSMC migration. A Analyses of VSMC migration under stimulation with bFGF $(10 \mathrm{ng} / \mathrm{ml})$ for $8 \mathrm{~h}$. Trajectories of VSMC migration from the origin (center of the graphs) to the endpoint. We performed three independent experiments (Epac ${ }^{+/+}$-VSMCs, $n=20,71$, and 55; Epac1 $1^{-1-}$-VSMCs, $n=23,40$, and 64) and found similar results among experiments. The sum of all data is shown (Epac1 $1^{+/+}$-VSMCs, $n=146$; Epac1 ${ }^{-1-}$-VSMCs, $\left.n=127\right)$. B Quantification of total path length of VSMCs. Data were obtained from three independent experiments (Control Epac1 ${ }^{+/+}$-VSMCs, $n=61,135$, and 65; Epac1 ${ }^{+/+}$-VSMCs treated with bFGF, $n=73,129$, and 46; Control
Epac1 $1^{-/-}$-VSMCs, $n=26,126$, and 41; Epac1 ${ }^{-/-}$-VSMCs treated with bFGF, $n=40,105$, and 21). Statistical analysis using a two-way ANOVA followed by Bonferroni's multiple comparison test indicated that all experiments had statistically similar results. The sum of all data is shown (Control Epac1 ${ }^{+/+}$-VSMCs, $n=261$; Epac1 ${ }^{+/+}$-VSMCs treated with bFGF, $n=248$; Control Epac1 $1^{-1-}$-VSMCs, $n=193$; Epac1 $^{-1-}$-VSMCs treated with bFGF, $\left.n=166\right)$. *** $p<0.0001$. NS indicates not significant. C Quantifications of FGFR1 protein expression in unstimulated VSMCs by western blotting. $n=5$. NS indicates not significant 
A

$\mathrm{Epac1}^{+/+}$
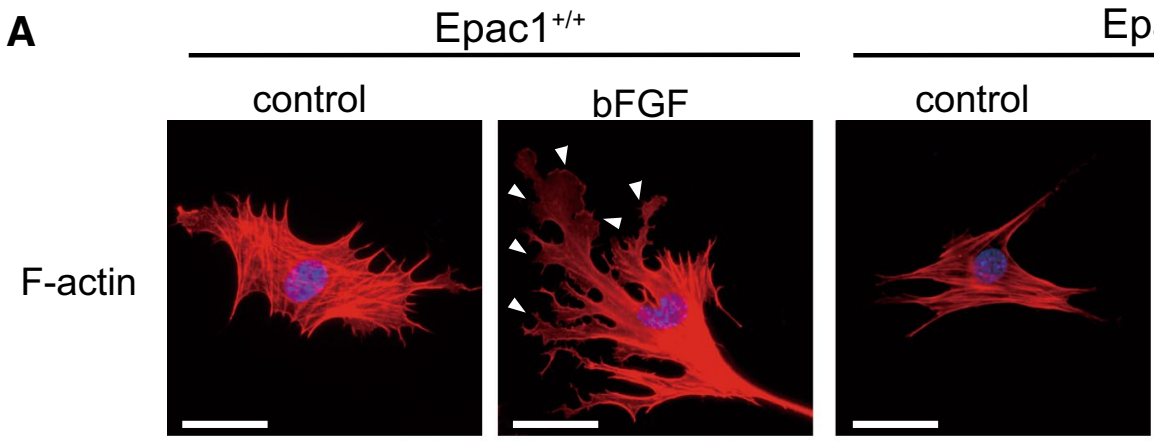

Epac1- $^{-1}$
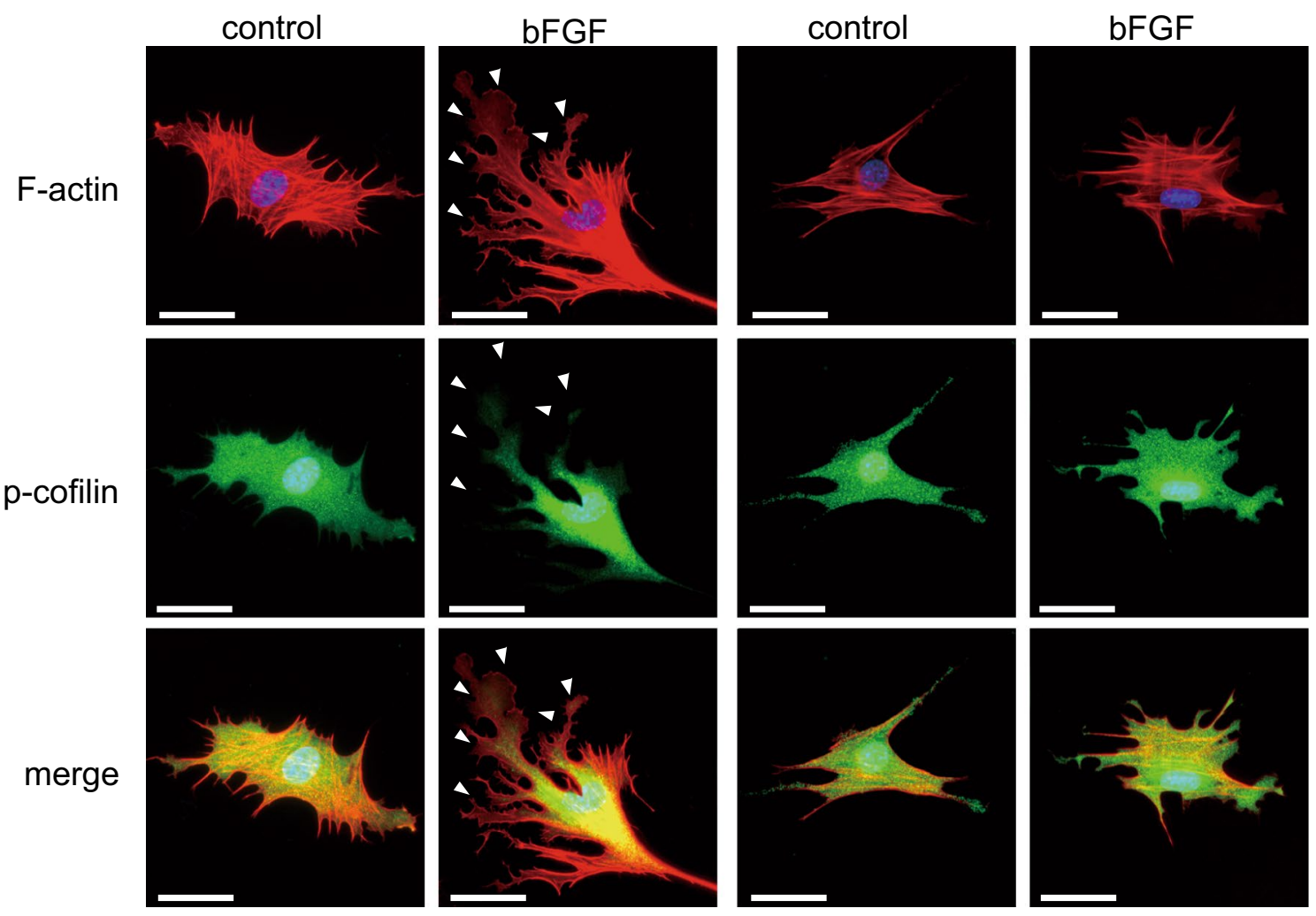

B

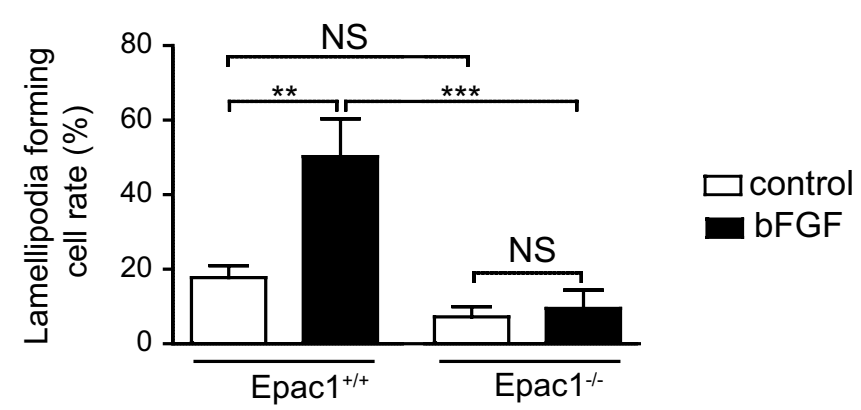

Fig. 2 Epac1 deficiency decreased bFGF-induced lamellipodia formation. A Representative images of lamellipodia formation in VSMCs. Upper panels: F-actin (red); middle panels: phosphorylated cofilin (p-cofilin, green); lower panels: merged images of F-actin and p-cofilin staining. Arrowheads indicate lamellipodia accompanied by dephosphorylated cofilin. Scale bars, $30 \mu \mathrm{m}$. B Quantification of the number of VSMCs with lamellipodia accom- panied by dephosphorylated cofilin. Lamellipodia-positive cell rates are presented as the percent of total cell number. $n=353$ (control Epac1 $^{+/+}$-VSMCs), 196 (Epac1 ${ }^{+/+}$-VSMCs treated with bFGF), 195 (control Epac1 ${ }^{-/-}$-VSMCs), and 463 (Epac1 ${ }^{-/-}$-VSMCs treated with bFGF). Data were obtained from more than four independent experiments. ${ }^{*} p<0.001 ; * * * p<0.0001$. NS indicates not significant

and their paths were obtained (Fig. 1a, Supplemental Movies I and II). The degree of bFGF-induced cell migration was smaller in Epac1 ${ }^{-/-}$-VSMCs than in Epac1 $1^{+/+}$-VSMCs (Fig. 1a, b). Fibroblast growth factor receptor 1 (FGFR1) mainly contributes to bFGF-induced VSMC migration [25]. Next, we examined whether FGFR1 expression was

We examined the migratory effect of bFGF on the VSMCs of Epac1 ${ }^{+/+}$mice $\left(E p a c 1^{+/+}\right.$-VSMCs) and Epac1 ${ }^{-/-}$mice (Epac1 $1^{-/-}$-VSMCs). Cell migration was monitored for $8 \mathrm{~h}$ 
A

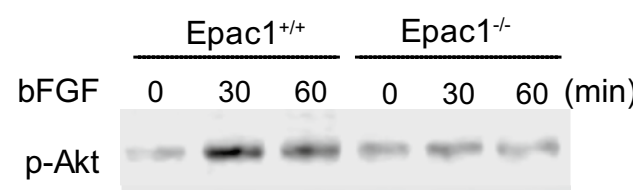

total-Akt

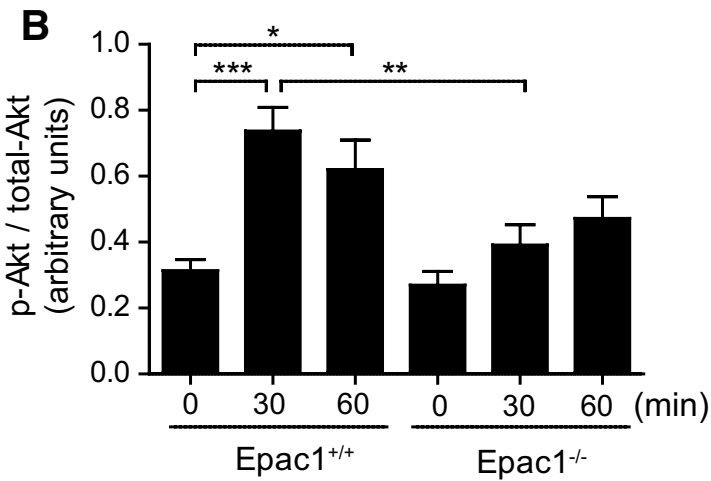

Fig. 3 Epac1 deficiency decreased bFGF-induced phosphorylation of Akt and GSK3 $\beta$. VSMCs were incubated with or without $10 \mathrm{ng} / \mathrm{ml}$ of bFGF for 30 or $60 \mathrm{~min}$. A Representative western blotting images of the phosphorylation of Akt (p-Akt) are shown. B Quantification of A,
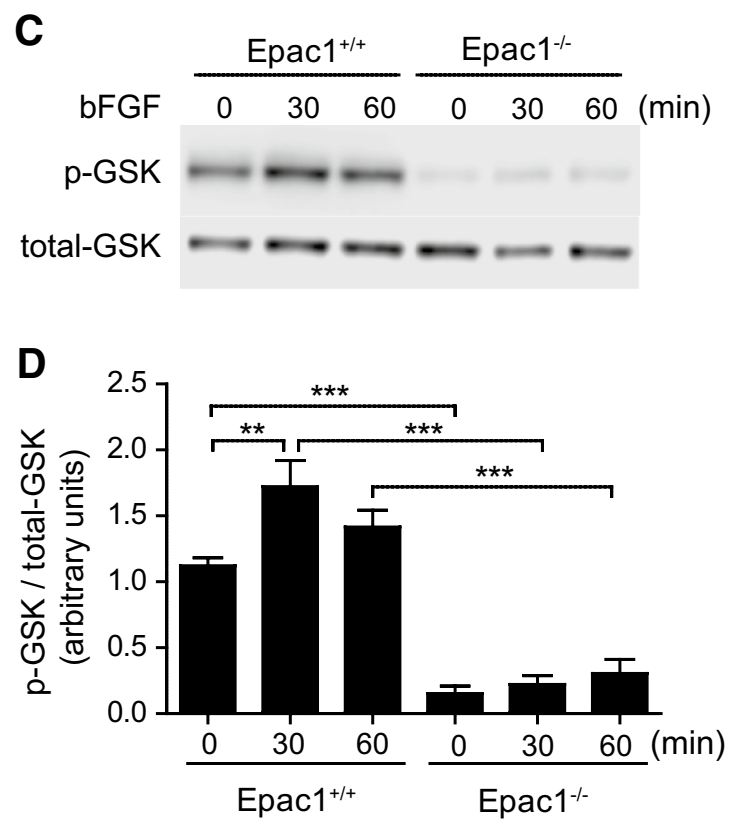

$n=6$. C Representative western blotting images of the phosphorylation of GSK3 $\beta$ (p-GSK3 $\beta$ ) are shown. D Quantification of $\mathbf{C}, n=6$. $* p<0.05 ; * * p<0.01 ; * * * p<0.001$

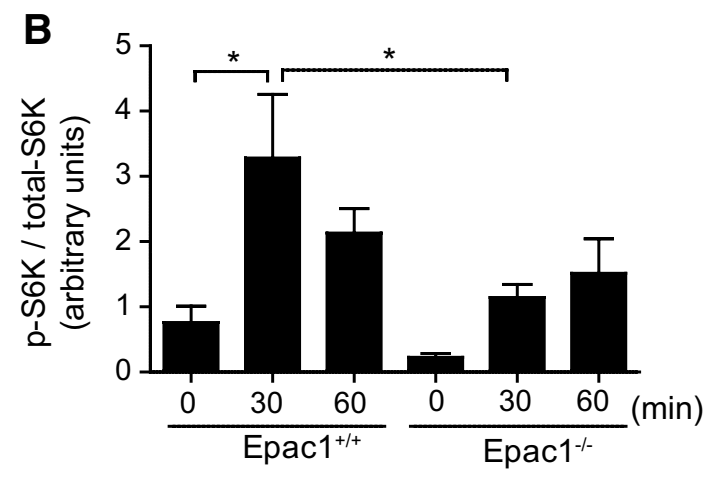

Fig. 4 bFGF-induced phosphorylation of S6 K and FOXO1 in Epac1 deficient VSMCs. VSMCs were incubated with or without $10 \mathrm{ng} / \mathrm{ml}$ of bFGF for 30 or $60 \mathrm{~min}$. A Representative western blotting images of the phosphorylation of S6 K (p-S6 K) are shown. B Quantification
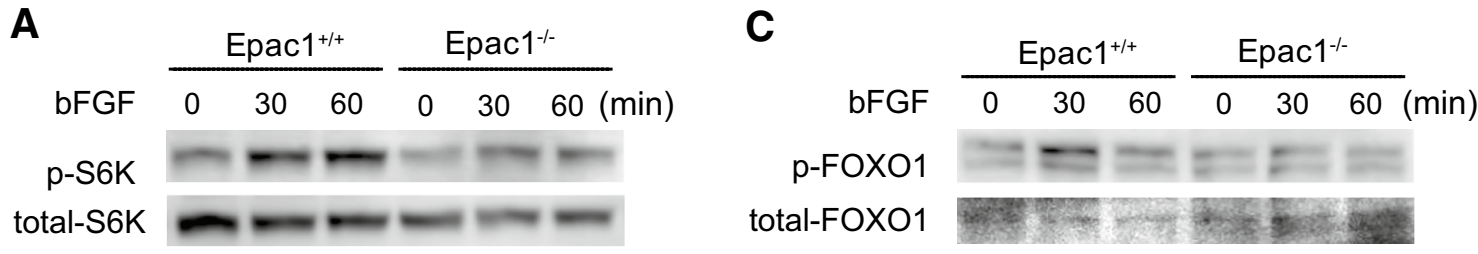

\footnotetext{
D
}

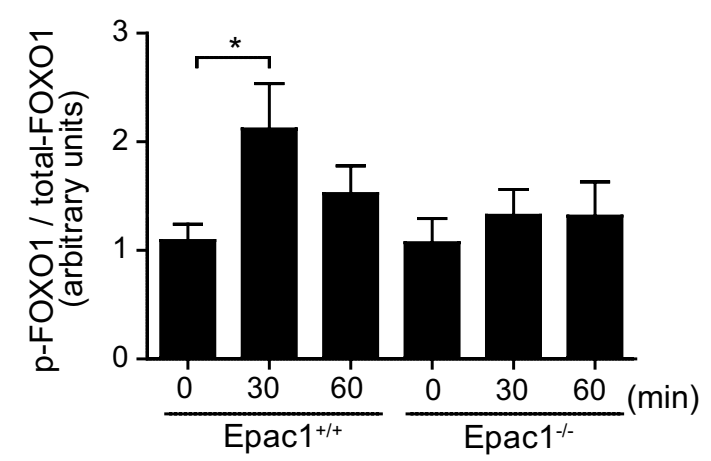

of $\mathbf{A}, n=4$. $\mathbf{C}$ Representative western blotting images of the phosphorylation of FOXO1 (p-FOXO1) are shown. D Quantification of C, $n=4 . * p<0.05$ 
affected by Epac1 deficiency; no difference was found in FGFR1 protein expression between Epac1 ${ }^{+/+}$- and $\mathrm{Epac}^{-/-}$-VSMCs (Fig. 1c).

\section{Epac1 deficiency decreased bFGF-induced lamellipodia formation}

Lamelliopodia with membrane protrusion play fundamental roles in cell migration [26]. We next examined the effect of Epac1 deficiency on bFGF-induced lamellipodia formation and cofilin dephosphorylation, which plays a critical role in lamellipodia formation [26]. Immunocytochemistry revealed that bFGF significantly increased lamellipodia formation and was accompanied by cofilin dephosphorylation in Epac1 $1^{+/+}$-VSMCs, but not in Epac1 $1^{-/-}$-VSMCs (Fig. 2). These results suggest that Epac1 is involved in bFGFinduced lamellipodia formation.

\section{Epac1 deficiency decreased bFGF-induced phosphorylation of Akt and GSK3 $\beta$}

It has been reported that bFGF activates PI3 K/Akt pathways, which further induces GSK3 $\beta$ phosphorylation, leading to cell migration [27, 28]. It is of note that PI3 K induces the phosphorylation of Akt at $\mathrm{Ser}^{473}$, thereby promoting the phosphorylation of GSK3 at Ser ${ }^{9}$, which inactivates GSK3 $\beta$ kinase activity [29]. We next assessed whether the phosphorylation of Akt at $\operatorname{Ser}^{473}$ and GSK3 $\beta$ at Ser $^{9}$ are inhibited by Epac1 deficiency. bFGF stimulation increased both Akt and GSK3 $\beta$ phosphorylation in Epac $1^{+/+}$VSMCs, and this effect was significantly inhibited in Epac1 $1^{-/-}$VSMCs (Fig. 3). No delayed enhancement of phosphorylation in Epac1 $^{-1-}$ VSMCs was observed.

It has been recognized that phosphorylation of PI3 K/ Akt induces S6 K and FOXO1 phosphorylation, which are related to protein synthesis and cell survival, respectively $[30,31]$. bFGF stimulation increased phosphorylation of S6 $\mathrm{K}$ at $\mathrm{Thr}^{389}$ in Epac1 ${ }^{+/+}$VSMCs, and this effect was significantly attenuated in Epac1 ${ }^{-/-}$VSMCs (Fig. 4a, b). Phosphorylation of FOXO1 at $\mathrm{Ser}^{256}$ was increased by bFGF stimulation in Epac1 ${ }^{+/+}$VSMCs. This effect was attenuated in Epac1 ${ }^{-/-}$VSMCs, although this attenuation did not reach significance (Fig. 4c, d).

\section{Epac1 deficiency suppressed intimal thickening and GSK3 $\beta$ phosphorylation}

Based on the in vitro results, we investigated the phosphorylation status of GSK3 $\beta$ in mechanical injury-induced intimal thickening in Epac1 ${ }^{+/+}$and Epac1 ${ }^{-/-}$mice. There was no morphological difference between the femoral arteries of Epac1 ${ }^{+/+}$or Epac1 $1^{-/-}$mice in basal conditions (upper panels of Fig. 5). The insertion of a large wire into the femoral arteries induced prominent intimal thickening in Epac $1^{+/+}$whereas this intimal thickening was attenuated in Epac $^{-/-}$mice (lower panels of Fig. 5), which was consistent with the results of previous reports [13, 14]. Immunocytochemistry demonstrated that phosphorylated GSK3 $\beta$ expression was attenuated in the area of intimal thickening in Epac $1^{-/-}$mice compared to that in $\mathrm{Epac}^{+/+}$mice (lower panels of Fig. 5).

\section{Discussion}

In the present study, we demonstrated that Epac1 deficiency attenuated the bFGF-induced phosphorylation of Akt and GSK3 $\beta$, cell migration, and lamellipodia formation in VSMCs. Epac1 deficiency reduced mechanical injuryinduced intimal thickening, which was accompanied by the decreased phosphorylation of GSK3 $\beta$. These data indicated that Epac1-mediated downstream signaling Akt/GSK3 $\beta$ is involved in bFGF-induced VSMC migration.

bFGF is the major modulator of VSMC migration and intimal thickening formation. It has been demonstrated that anti-bFGF IgG administration caused an approximately 50\% reduction in intimal thickening [32]. Significant inhibition of intimal thickening was observed in the artery treated with the intraluminal adenoviral gene transfer of an antisense bFGF [33]. Emerging evidence suggests that bFGF and Epac activate many cellular outcomes, including migration via PI3 K/Akt signaling [14-18, 20-23]. One report suggested that Epac1 increases the migration of endothelial cells via bFGF-mediated paracrine signaling [34]. In this study, Epac1 silencing inhibited the binding of bFGF to FGFR through attenuation of N-sulfation of heparin sulfate chains. The interaction between bFGF and Epac signaling pathways, however, is largely unknown.

The present study demonstrated that the bFGF-mediated phosphorylation of Akt and GSK3 $\beta$ and the migration in VSMCs were significantly attenuated under the Epac1deficient condition, suggesting an association between Epac1- and bFGF-mediated downstream signaling. Epac1 is activated by direct cAMP binding and mediates a wide range of cellular responses [35, 36]. A previous paper proposed the mechanisms of bFGF stimulation-mediated cAMP production [37]. FGFR1 activates the PLC $\gamma /$ diacylglycerol pathway, enhancing $\mathrm{Ca}^{2+}$ entry through voltage-gated calcium channels, and $\mathrm{Ca}^{2+} /$ calmodulin could then activate calcium-sensitive adenylyl cyclases, producing cAMP [37]. Although this paper proposed this signaling cascade, the concept was not supported by the experimental data. It is, however, recognized that bFGF is not directly involved in the elevation of the intracellular concentration of cAMP [38-40]. Based on these findings, there is currently no evidence that bFGF-FGFR signaling directly regulates Epac1 


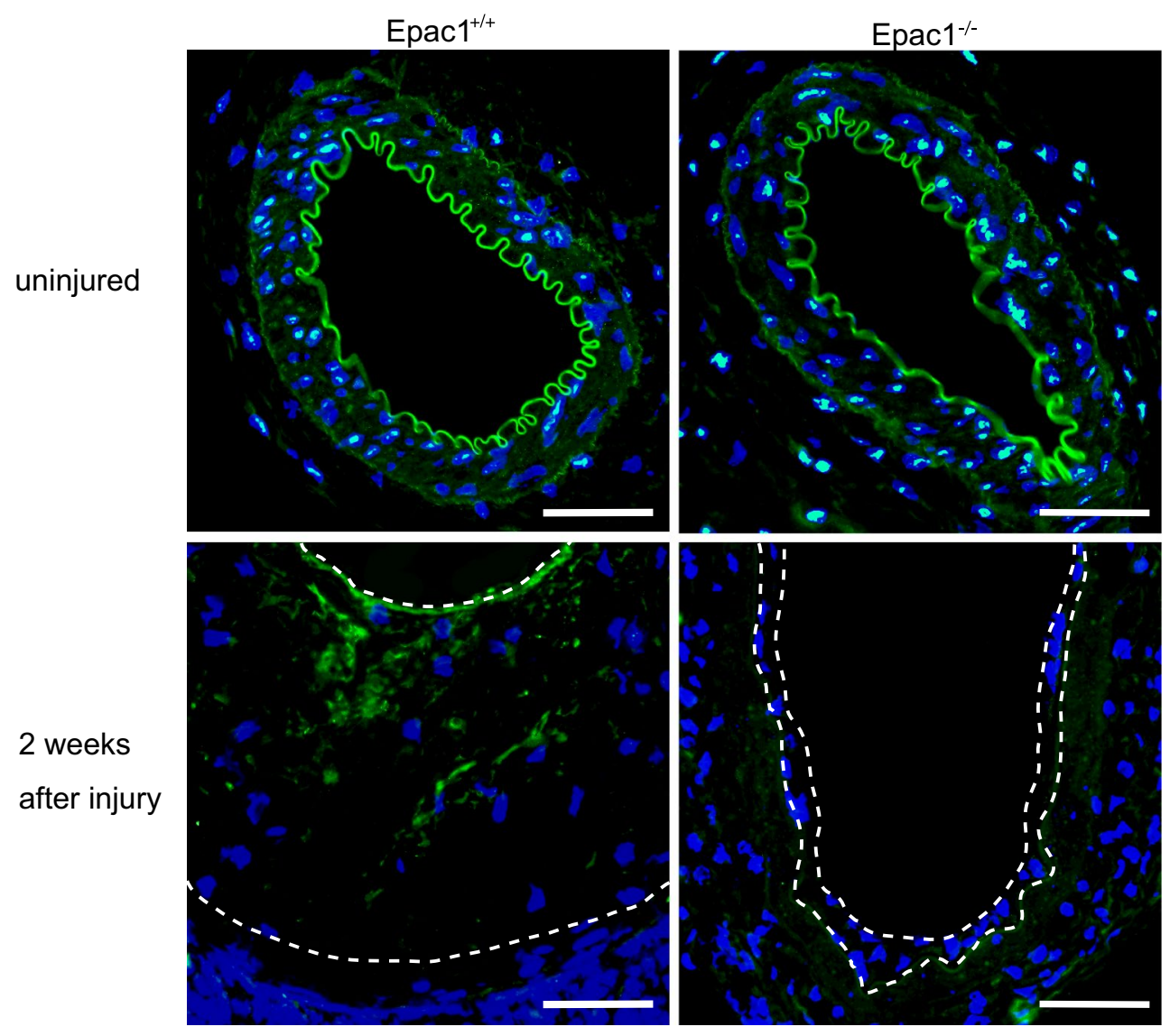

Fig. 5 Epac1 deficiency suppressed intimal thickening and GSK3 $\beta$ phosphorylation. Representative images of immunohistochemistry for GSK3 $\beta$ phosphorylation in the cross-sections of the uninjured (upper panels) and wire-injured (lower panels) femoral arteries of Epac1 ${ }^{+/+}$

activation. We assume that the bFGF-mediated downstream signaling interacts with the Epac1-mediated intracellular signaling pathways. We do not, however, know the exact molecular mechanisms of this interaction. Further study on small $\mathrm{G}$ protein Rap and PI3 K is needed to determine how the bFGF and Epac1 signaling pathways interact.

In the present study, we found low levels of GSK3 $\beta$ phosphorylation in Epac1 ${ }^{-/-}$-VSMCs with or without bFGF stimulation. GSK3 $\beta$ ubiquitously expresses serine/threonine kinase and has a high basal activity in resting cells. GSK3 $\beta$ plays roles in many biological processes, including cell polarity, microtubule dynamics, and cell migration [41-43]. The importance of GSK3 $\beta$ inactivation in vascular remodeling has also been reported [44]. In a rat balloon catheter injury model, the expression of phosphorylated GSK3 $\beta$ (inactivation) was markedly increased in the intimal thickening area, and the constitutively active $G S K 3 \beta$ gene transfer resulted in reduced intimal thickening formation [44]. During intimal thickening formation, VSMC apoptosis was and $\mathrm{Epac}^{-/-}$mice. Immunoreaction against GSK3 $\beta$ phosphorylation is shown in green. The nucleus was visualized in blue by Hoechst stain. The area between the white dotted lines indicates intimal thickening. Scale bars, $50 \mu \mathrm{m}$

inhibited by the upregulation of glucose metabolism and is linked to the inactivation of GSK3 $\beta$ [45].

The role of Epac in GSK3 $\beta$ activation has been controversial. Studies using skeletal muscle cells, hippocampal slices, and cultured microglia demonstrated no effect of Epac on GSK3 $\beta$ activation [46-48]. Two papers, however, showed that Epac or Epac1 inactivated GSK3 $\beta$ in isolated rat heart and melanoma cells [27, 49]. Akt is a major upstream regulator that results in the inactivation of GSK3 $\beta$ through the phosphorylation of the N-terminal $\operatorname{Ser}^{9}$ [29]. Epac promoted tubulin polymerization via activation of the PI3 K/ Akt/GSK3 $\beta$ pathway [27]. These data suggest that Epacmediated GSK3 $\beta$ activation depends on the cell type and upstream of Epac signaling. Our data showed that, under basal conditions, the degree of phosphorylation of Akt was similar between Epac1 $1^{+/+}$and Epac1 ${ }^{-/-}$-VSMCs, whereas the expression level of phosphorylated GSK3 $\beta$ was lower in Epac1 $1^{-/-}$-VSMCs than in Epac1 ${ }^{+/+}$-VSMCs. The mitogenactivated protein kinase cascade and the Wnt pathway are the upstream signaling of GSK3 $\beta$, as well as the PI3 K/Akt 
axis [50, 51]. In addition to Akt activation, Epac-mediated upstream signaling that activates GSK $3 \beta$ may exist.

GSK3 $\beta$ inactivation leads to activation of the $\beta$-catenin signaling pathway via the accumulation of $\beta$-catenin in the nucleus, which regulates gene expression and a variety of cell activities, including cell migration [52]. It has been reported that bFGF promotes skin fibroblast migration via the GSK3 $\beta / \beta$-catenin signaling pathway [15]. An elevated level of active $\beta$-catenin was detected at the sites of intimal thickening after vascular injury, and inhibition of $\beta$-catenin decreased neointima formation after injury [53]. These data suggest the possible role of $\beta$-catenin in VSMC migration. The mechanisms connecting GSK3 $\beta$ inactivation and VSMC migration need to be determined in a future study.

In addition to cell migration, Akt signaling regulates protein synthesis and cell survival or proliferation via Akt/S6 K and Akt/FOXO1 signaling pathways, respectively [54]. Our data suggested that $\mathrm{S} 6 \mathrm{~K}$-mediated protein synthesis and FOXO1-mediated cell survival or proliferation were attenuated in Epac1 ${ }^{-1-}$-VSMCs. Although a few papers indicated the involvement of S6 K and FOXO1 in intimal thickening formation $[55,56]$ and there is currently no direct evidence demonstrating causal relationship between these signaling pathways and vascular intimal thickening formation, Epac1mediated regulation of these signaling pathways would be important for a future study.

In conclusion, Epac1 plays a role in bFGF-induced VSMC migration via Akt/GSK3 $\beta$ phosphorylation. Both our present study and our previous study [13] suggest that Epac1 is involved in PDGF-BB and bFGF-mediated VSMC migration. It has been reported that Epac1 was upregulated during injury-induced intimal thickening formation [10] and that Epac1 deficiency or the pharmacological inhibition of Epac attenuated intimal thickening formation in a mouse model of vascular injury [13, 14]. Epac1 may be a future target for therapy to inhibit vascular intimal thickening.

Acknowledgements The authors are grateful to Yuka Sawada (Yokohama City University) for histological analysis.

Funding sources This study was funded by MEXT/JSPS KAKENHI (YK, JP17K08976; UY, JP17K19403, JP16H05358, JP15H05761; YI, JPH1605300), the Takeda Science Foundation (YK), the Japan Agency for Medical Research and Development (AMED) (YI, 66890007, 66891153), and the Kitsuen Research Foundation (YI, 71890005).

\section{References}

1. Schwartz SM (1997) Perspectives series: cell adhesion in vascular biology. Smooth muscle migration in atherosclerosis and restenosis. J Clin Investig 99:2814-2816

2. Newby AC, Zaltsman AB (2000) Molecular mechanisms in intimal hyperplasia. J Pathol 190:300-309
3. Stolker JM, Kennedy KF, Lindsey JB, Marso SP, Pencina MJ, Cutlip DE, Mauri L, Kleiman NS, Cohen DJ, Investigators E (2010) Predicting restenosis of drug-eluting stents placed in real-world clinical practice: derivation and validation of a risk model from the EVENT registry. Circ Cardiovasc Interv 3:327-334

4. Finn AV, Joner M, Nakazawa G, Kolodgie F, Newell J, John MC, Gold HK, Virmani R (2007) Pathological correlates of late drugeluting stent thrombosis: strut coverage as a marker of endothelialization. Circulation 115:2435-2441

5. Casscells W (1992) Migration of smooth muscle and endothelial cells. Critical events in restenosis. Circulation 86:723-729

6. Jackson CL, Reidy MA (1993) Basic fibroblast growth factor: its role in the control of smooth muscle cell migration. Am J Pathol 143:1024-1031

7. Schroder K, Helmcke I, Palfi K, Krause KH, Busse R, Brandes RP (2007) Nox 1 mediates basic fibroblast growth factor-induced migration of vascular smooth muscle cells. Arterioscler Thromb Vasc Biol 27:1736-1743

8. Lindner V, Lappi DA, Baird A, Majack RA, Reidy MA (1991) Role of basic fibroblast growth factor in vascular lesion formation. Circ Res 68:106-113

9. Lindner V (1995) Role of basic fibroblast growth factor and platelet-derived growth factor (B-chain) in neointima formation after arterial injury. Z Kardiol 84(Suppl 4):137-144

10. Yokoyama U, Minamisawa S, Quan H, Akaike T, Jin M, Otsu K, Ulucan C, Wang X, Baljinnyam E, Takaoka M, Sata M, Ishikawa $Y$ (2008) Epac1 is upregulated during neointima formation and promotes vascular smooth muscle cell migration. Am J Physiol Heart Circ Physiol 295:H1547-H1555

11. Yokoyama U, Minamisawa S, Quan H, Akaike T, Suzuki S, Jin M, Jiao Q, Watanabe M, Otsu K, Iwasaki S, Nishimaki S, Sato M, Ishikawa Y (2008) Prostaglandin E2-activated Epac promotes neointimal formation of the rat ductus arteriosus by a process distinct from that of cAMP-dependent protein kinase A. J Biol Chem 283:28702-28709

12. Yokoyama U, Patel HH, Lai NC, Aroonsakool N, Roth DM, Insel PA (2008) The cyclic AMP effector Epac integrates pro- and antifibrotic signals. Proc Natl Acad Sci USA 105:6386-6391

13. Kato Y, Yokoyama U, Yanai C, Ishige R, Kurotaki D, Umemura M, Fujita T, Kubota T, Okumura S, Sata M, Tamura T, Ishikawa Y (2015) Epac1 deficiency attenuated vascular smooth muscle cell migration and neointimal formation. Arterioscler Thromb Vasc Biol 35:2617-2625

14. Wang H, Robichaux WG, Wang Z, Mei FC, Cai M, Du G, Chen J, Cheng X (2016) Inhibition of Epac1 suppresses mitochondrial fission and reduces neointima formation induced by vascular injury. Sci Rep 6:36552

15. Wang X, Zhu Y, Sun C, Wang T, Shen Y, Cai W, Sun J, Chi L, Wang H, Song N, Niu C, Shen J, Cong W, Zhu Z, Xuan Y, Li X, Jin L (2017) Feedback activation of basic fibroblast growth factor signaling via the Wnt/beta-catenin pathway in skin fibroblasts. Front Pharmacol 8:32

16. Schmidt A, Ladage D, Schinkothe T, Klausmann U, Ulrichs C, Klinz FJ, Brixius K, Arnhold S, Desai B, Mehlhorn U, Schwinger RH, Staib P, Addicks K, Bloch W (2006) Basic fibroblast growth factor controls migration in human mesenchymal stem cells. Stem Cells 24:1750-1758

17. Shi H, Lin B, Huang Y, Wu J, Zhang H, Lin C, Wang Z, Zhu J, Zhao Y, Fu X, Lou Z, Li X, Xiao J (2016) Basic fibroblast growth factor promotes melanocyte migration via activating PI3 K/AktRac1-FAK-JNK and ERK signaling pathways. IUBMB Life 68:735-747

18. Shimabukuro Y, Terashima H, Takedachi M, Maeda K, Nakamura T, Sawada K, Kobashi M, Awata T, Oohara H, Kawahara T, Iwayama T, Hashikawa T, Yanagita M, Yamada S, Murakami S 
(2011) Fibroblast growth factor-2 stimulates directed migration of periodontal ligament cells via PI3 K/AKT signaling and CD44/ hyaluronan interaction. J Cell Physiol 226:809-821

19. Shigematsu K, Koyama H, Olson NE, Cho A, Reidy MA (2000) Phosphatidylinositol 3-kinase signaling is important for smooth muscle cell replication after arterial injury. Arterioscler Thromb Vasc Biol 20:2373-2378

20. Jing H, Yen JH, Ganea D (2004) A novel signaling pathway mediates the inhibition of CCL3/4 expression by prostaglandin E2. J Biol Chem 279:55176-55186

21. Namkoong S, Kim CK, Cho YL, Kim JH, Lee H, Ha KS, Choe J, Kim PH, Won MH, Kwon YG, Shim EB, Kim YM (2009) Forskolin increases angiogenesis through the coordinated crosstalk of PKA-dependent VEGF expression and Epac-mediated PI3 K/Akt/eNOS signaling. Cell Signal 21:906-915

22. Villarreal F, Epperson SA, Ramirez-Sanchez I, Yamazaki KG, Brunton LL (2009) Regulation of cardiac fibroblast collagen synthesis by adenosine: roles for Epac and PI3 K. Am J Physiol Cell Physiol 296:C1178-C1184

23. Baviera AM, Zanon NM, Navegantes LC, Kettelhut IC (2010) Involvement of cAMP/Epac/PI3K-dependent pathway in the antiproteolytic effect of epinephrine on rat skeletal muscle. Mol Cell Endocrinol 315:104-112

24. Suzuki S, Yokoyama U, Abe T, Kiyonari H, Yamashita N, Kato Y, Kurotani R, Sato M, Okumura S, Ishikawa Y (2010) Differential roles of Epac in regulating cell death in neuronal and myocardial cells. J Biol Chem 285:24248-24259

25. Rauch BH, Millette E, Kenagy RD, Daum G, Fischer JW, Clowes AW (2005) Syndecan-4 is required for thrombininduced migration and proliferation in human vascular smooth muscle cells. J Biol Chem 280:17507-17511

26. Ghosh M, Song X, Mouneimne G, Sidani M, Lawrence DS, Condeelis JS (2004) Cofilin promotes actin polymerization and defines the direction of cell motility. Science 304:743-746

27. Baljinnyam E, Iwatsubo K, Kurotani R, Wang X, Ulucan C, Iwatsubo M, Lagunoff D, Ishikawa Y (2009) Epac increases melanoma cell migration by a heparan sulfate-related mechanism. Am J Physiol Cell Physiol 297:C802-C813

28. Liu ZC, Wang HS, Zhang G, Liu H, Chen XH, Zhang F, Chen DY, Cai SH, Du J (2014) AKT/GSK-3beta regulates stability and transcription of snail which is crucial for bFGF-induced epithelial-mesenchymal transition of prostate cancer cells. Biochim Biophys Acta 1840:3096-3105

29. Cohen P, Frame S (2001) The renaissance of GSK3. Nat Rev Mol Cell Biol 2:769-776

30. Pullen N, Thomas G (1997) The modular phosphorylation and activation of p70s6k. FEBS Lett 410:78-82

31. Huang H, Tindall DJ (2007) Dynamic FoxO transcription factors. J Cell Sci 120:2479-2487

32. Rutherford C, Martin W, Salame M, Carrier M, Anggard E, Ferns G (1997) Substantial inhibition of neo-intimal response to balloon injury in the rat carotid artery using a combination of antibodies to platelet-derived growth factor-BB and basic fibroblast growth factor. Atherosclerosis 130:45-51

33. Hanna AK, Fox JC, Neschis DG, Safford SD, Swain JL, Golden MA (1997) Antisense basic fibroblast growth factor gene transfer reduces neointimal thickening after arterial injury. J Vasc Surg 25:320-325

34. Baljinnyam E, Umemura M, Chuang C, De Lorenzo MS, Iwatsubo M, Chen S, Goydos JS, Ishikawa Y, Whitelock JM, Iwatsubo K (2014) Epac1 increases migration of endothelial cells and melanoma cells via FGF2-mediated paracrine signaling. Pigment Cell Melanoma Res 27:611-620

35. de Rooij J, Zwartkruis FJ, Verheijen MH, Cool RH, Nijman SM, Wittinghofer A, Bos JL (1998) Epac is a Rap1 guanine-nucleotide-exchange factor directly activated by cyclic AMP. Nature 396:474-477

36. Gloerich M, Bos JL (2010) Epac: defining a new mechanism for cAMP action. Annu Rev Pharmacol Toxicol 50:355-375

37. Soto I, Rosenthal JJ, Blagburn JM, Blanco RE (2006) Fibroblast growth factor 2 applied to the optic nerve after axotomy upregulates $\mathrm{BDNF}$ and TrkB in ganglion cells by activating the ERK and PKA signaling pathways. J Neurochem 96:82-96

38. Pursiheimo JP, Jalkanen M, Tasken K, Jaakkola P (2000) Involvement of protein kinase A in fibroblast growth factor2-activated transcription. Proc Natl Acad Sci USA 97:168-173

39. Yoshimata T, Yoneyama A, Jin-no Y, Tamai N, Kamiya Y (1999) Effects of dehydroepiandrosterone on mitogen-activated protein kinase in human aortic smooth muscle cells. Life Sci 65:431-440

40. Logan A, Logan SD (1991) Studies on the mechanisms of signalling and inhibition by pertussis toxin of fibroblast growth factor-stimulated mitogenesis in Balb/c 3T3 cells. Cell Signal $3: 215-223$

41. Jiang H, Guo W, Liang X, Rao Y (2005) Both the establishment and the maintenance of neuronal polarity require active mechanisms: critical roles of GSK-3beta and its upstream regulators. Cell 120:123-135

42. Doble BW, Woodgett JR (2003) GSK-3: tricks of the trade for a multi-tasking kinase. J Cell Sci 116:1175-1186

43. Etienne-Manneville S, Hall A (2003) Cdc42 regulates GSK3 beta and adenomatous polyposis coli to control cell polarity. Nature 421:753-756

44. Park KW, Yang HM, Youn SW, Yang HJ, Chae IH, Oh BH, Lee MM, Park YB, Choi YS, Kim HS, Walsh K (2003) Constitutively active glycogen synthase kinase-3beta gene transfer sustains apoptosis, inhibits proliferation of vascular smooth muscle cells, and reduces neointima formation after balloon injury in rats. Arterioscler Thromb Vasc Biol 23:1364-1369

45. Hall JL, Chatham JC, Eldar-Finkelman H, Gibbons GH (2001) Upregulation of glucose metabolism during intimal lesion formation is coupled to the inhibition of vascular smooth muscle cell apoptosis. Role of GSK3beta. Diabetes 50:1171-1179

46. Jensen J, Brennesvik EO, Lai YC, Shepherd PR (2007) GSK3beta regulation in skeletal muscles by adrenaline and insulin: evidence that PKA and PKB regulate different pools of GSK-3. Cell Signal 19:204-210

47. Ster J, de Bock F, Bertaso F, Abitbol K, Daniel H, Bockaert J, Fagni L (2009) Epac mediates PACAP-dependent long-term depression in the hippocampus. J Physiol 587:101-113

48. Liu J, Zhao X, Cao J, Xue Q, Feng X, Liu X, Zhang F, Yu B (2011) Differential roles of PKA and Epac on the production of cytokines in the endotoxin-stimulated primary cultured microglia. J Mol Neurosci MN 45:186-193

49. Lee TM, Lin SZ, Chang NC (2013) Both PKA and Epac pathways mediate $\mathrm{N}$-acetylcysteine-induced Connexin 43 preservation in rats with myocardial infarction. PLoS One 8:e71878

50. Sutherland C, Leighton IA, Cohen P (1993) Inactivation of glycogen synthase kinase-3 beta by phosphorylation: new kinase connections in insulin and growth-factor signalling. Biochem J 296(Pt 1):15-19

51. Cook D, Fry MJ, Hughes K, Sumathipala R, Woodgett JR, Dale TC (1996) Wingless inactivates glycogen synthase kinase-3 via an intracellular signalling pathway which involves a protein kinase C. EMBO J 15:4526-4536

52. Gordon MD, Nusse R (2006) Wnt signaling: multiple pathways, multiple receptors, and multiple transcription factors. J Biol Chem 281:22429-22433

53. Riascos-Bernal DF, Chinnasamy P, Gross JN, Almonte V, Egana-Gorrono L, Parikh D, Jayakumar S, Guo L, Sibinga NES (2017) Inhibition of smooth muscle beta-catenin hinders 
neointima formation after vascular injury. Arterioscler Thromb Vasc Biol 37:879-888

54. Manning BD, Cantley LC (2007) AKT/PKB signaling: navigating downstream. Cell 129:1261-1274

55. Zhu LH, Huang L, Zhang X, Zhang P, Zhang SM, Guan H, Zhang Y, Zhu XY, Tian S, Deng K, Li H (2015) Mindin regulates vascular smooth muscle cell phenotype and prevents neointima formation. Clin Sci 129:129-145
56. Wang Y, Bai Y, Qin L, Zhang P, Yi T, Teesdale SA, Zhao L, Pober JS, Tellides G (2007) Interferon-gamma induces human vascular smooth muscle cell proliferation and intimal expansion by phosphatidylinositol 3-kinase dependent mammalian target of rapamycin raptor complex 1 activation. Circ Res 101:560-569 